\title{
From National Social Science Foundation Projects to Knowledge Production of Library and Information
}

\author{
Hui Wang \\ University Library, Jilin Agricultural University, 130118 Changchun, PR China \\ E-mail.13104452100@163.com
}

\begin{abstract}
The National Social Science Foundation Projects are the only research projects regarding philosophy, social sciences and humanities in national level. These funds have also been used as a measure and an important indicator of academic research capacity for schools and the research teams. Since 1994 Library and Information and Documentation Science have been included into the supporting scope of National Social Science Funds. In recent years library and Information Studies developed rapidly. Herein we analyzed the current state of development of Library and Information Science from the viewpoints of project units, project area, expected research outputs.
\end{abstract}

Keywords-National Social Science Foundation Project;Library and Information Science; Knowledge Production

\section{INTRODUCTION}

National Social Science Foundation, established in 1991 and under the guidance of the National Planning Office of Philosophical and Social Sciences, is one of China's main channels to support basic scientific research. National Social Science Fund supports 23 disciplinary Planning Evaluation Teams including Marxism, scientific socialism, party's history, party's construction, philosophy, economic theory, Chinese history, world history, Journalism and Communication Studies, Library and Information and Documentation sciences. In 1994, the National Social Science Foundation established and funded the Library and Information and Documentation Sciences. Projects funded by the National Social Science Foundation reflect current situation, developmental track and future trends of library, information and documentation sciences.

\section{THE RELATIONSHIP BETWEEN KNOWLEDGE PRODUCTION AND FUNDS}

Fund mainly refers to grants established for a purpose including trust funds, provident funds, insurance funds, pension funds, and other funds from foundations.

Since the Organization for Economic Co-operation and Development (OECD) proposed "knowledge-based economy" conception in the "1996 Annual Science, Technology and Industry Outlook", projects regarding knowledge and knowledge production have been paid great attention and under hot discussion in academic community. The production of education knowledge is mainly root in scientific research activities. Therefore, we should pay primary attention to scientific research activities.
Scientific research activities require and are largely dependent on the support from Funds, which provide economic support and nice environment in the academic research. Thus funds are essential in academic research. Impact of Funds in scientific research activities increases more and more, which become an important measure for scientific research ability of academic research groups or school, especially for those significant funds. However, a major the problem associated with funds is its difficulty to get funded, which further shows the necessity of research grants for scientific research activities.

Funding from the national social sciences foundation has a guidance effect for scientific research activities, which reflects the current macroscopic situation, developmental path of the research activities. On the one hand, science foundation relieves of the economic pressure and creates good economic conditions for scientific research activities, on the other hand also contributes to the progress and development of research activities.

The supporting scope of the National Social Science Foundation is for the whole country, with the special focus toward scholars working in institutes that possess good research environment and conditions. In recent years, because the central leading committee of the party paid more attention to this issue, the strength of the National Social Science Fund Projects is constantly enhanced. Consequently its total funds, coverage, and impact have been greatly improved. Number of subjects and projects funded by the NSSF continually increase; project management system of the funds is improving. Moreover, excellent research and a number of excellent research personnel the country has increasingly appeared. The guidance quality, authority and exemplary properties of National Social Science Fund projects are also getting stronger. This government funding as a financing support made a very important contribution for the smooth conduct of research activities. National Social Science Foundation offers education, art, and military science as the three main disciplines, forming six categories including major projects, annual project, specially commissioned projects, post-funded projects, the western project, the translation of Chinese academic projects. It mainly supports researchers from the country's universities, Chinese Academy of Social Sciences, party school, party and government agencies, research departments, military academies, in addition, social scientists and scholars from remote and ethnic minority areas are also considered. Generally the projects funded by the national social 
science foundation have great impact and practicability. Since the establishment of the National Social Science Fund, 2.65 billion CNY have been invested toward 24,283 projects, with research outputs 45,000 items (3500 of them have been awarded above the provincial level). These high impact research achievements represent the highest level of scientific research in the country.

\section{NATIONAL INFORMATION KNOWLEDGE PRODUCTION AND THE NATIONAL SOCIAL SCIENCE FOUNDATION}

National Social Science Fund Projects for project financing funds not only eased the research activities regarding economic issues, while the regional funded projects also reflect the scientific productivity of the projects.

\section{A. Development of the Information Topics in National Library}

In 1994, National Social Science Foundation included the "Library, Information and Documentation Science" as a new funding class, which can be further divided into five categories: major, key, general, youth and self-financing projects. The establishment of the Library and Information subjects in National Social Science Foundation indicates the constant progress of libraries, science and technology. From 1994 to 2010 (ca. 16 years), the National information disciplines funded obtained financial supports as follows: 553 projects in total, 34 major projects, 374 general projects, 136 youth projects, and 9 self-funded projects. According to survey data, the number of funded projects of library and information sciences gradually increased, especially in recent years the number of the project approval improved significantly. The project approval number is eight times in 2010 than in 1994. Apparently, the funding from the National Social Science Foundation has played a catalytic role in development of national library and information subjects as the increase of project approval number is dependent on the state financial support.

Major and Key projects mainly obtained by the national library, Wuhan University, Peking University, Renmin University of China, Party School of the CPC Central Committee, the Academy of Social Sciences and several other institutes. These institutes may have two advantages: First, the strength of scientific research and the ability of researchers show competitive advantage; Second, the advantage in project selection. The main direction of the funded major and key projects mainly concerns the reform and opening-up policy and socialist modernization theory, which means that funds mainly support studies related to current hot and focus issues. To get invested, the major colleges and universities must show their excellent scientific research strength.For instance, scientific research and technology of Information studies in Wuhan University Library is very mature, consequently its information resource research center was approved by the Ministry of Education as humanities and social science research base, where they have excellent technology and talents.

\section{B. The project approval system for national library and information studies}

According to the survey, the NSSF systems primarily support colleges and universities, followed by the social academy, party school, military, public library systems (including archives, information centers, etc.), and other research institutions, showing that colleges and universities are the focus of the national social science Foundation.

During the last 21 years, the funded projects within six different funding systems concerning national library and information are all increasing, which is about the same as situation we mentioned above for national social science funds. Nevertheless, the funding ratio of the projects remained basically unchanged, where colleges and universities are the major objects for project approval.

\section{Expected research output analysis}

National Social Science Foundation points out that the expected research outputs mainly are monographs, translations, papers, research reports, reference books, and computer software. Based on the survey, among these results, papers and research reports are the major forms. Specifically, papers and research reports account for $27.31 \%, 14.32 \%$ of which are research reports; monographs and research reports, accounting for $12.84 \%$, the total proportion of other forms are less than $50 \%$ in total. For the expected research outputs, different forms correspond to different characteristics. Research reports and papers relatively require short time period for instance one year, where scholars have enough time to complete their research expected results. Generally most of people choose this option for application related researches. For major and key research, monographs and research reports are the recommended form for the expected results, as monographs and research reports are suitable for explanation of detailed and specific process. Moreover, researchers are able to integrate their own theoretical and systematicness with the monographs. Concerning national library and information projects, the expected research results are more suitable in the form of papers and research reports. Library and information researches require relatively a short study period, where the studies carried out by the researchers are mainly countermeasures for specific problems. Although monographs are also used, most of researchers prefer papers and research reports.

\section{Distribution area analysis}

The national social science foundation pays attention to foster young social science researcher and research in remote and ethnic minority areas, with special focus on social scientists having good study conditions and working in active universities and research institutions.

Data show that the number of project approval of a region is tightly related to the research strength, economic status, and education level in the area.

Hainan Province is the only province where none of project was funded; all the other provinces are more or less funded by the national social science foundation, although they are highly unevenly distributed. For example, not a single project was funded in Hainan province. Besides, Qinghai province get a single project funded(0.13\%); Beijing has 100 times more projects 
funded as compared to Qinghai (24.86\%); Hubei Province was ranked No. 2 (12.79 \%); Shanghai, Jiangsu, Guangdong, and Henan were ranked No.3, 4, 5, and 6, respectively. The large differences in regional distribution are greatly related to the local economic, cultural, and education conditions. Beijing is the capital of China and a gathering place for institutions of higher learning, such as Peking University, Tsinghua University, Renmin University of China, etc. are located in the this area. The economy and culture are relatively developed, with large amount of excellent talents and strength in scientific research and technology. These factors can explain the large amount of project get supported in this region. Shanghai is a bustling commercial center and economically developed, A number of famous institutes with strength in scientific research such as Fudan University are located in this city, which indicates a plenty of competitive advantages. Other provinces such as Hubei, Jiangsu, Guangdong, Henan, and Hunan are all having competitive advantage as they are all developed in economy, strong in culture and education, and having famous Institute localized. As for Qinghai, Inner Mongolia and other places, the remoteness, economic weakness, low strength in scientific research is low, and small number of the local institutions, explain the low number of project approval. Anyway, the number of funded projects is associated with a variety of factors such as local economic status, cultural and education level.

\section{E. Institute distribution analysis}

National social science foundation is regarded as a high level grant, which is an important criterion for measuring scientific research strength of schools or research teams. According to the survey, colleges and universities, important research institutions, national libraries, archives and information centers occupied the most of project approval of library, information and knowledge production, where the colleges and universities hold a large quantity of funds, suggesting their high status in library and information related studies.

In the survey data, we can find that $86 \%$ of the project approval institutes are of colleges and universities except for Beijing, where a relatively small proportion of the project approval institutes are in universities. This is because Beijing as our capital is a gathering place for political, economic, cultural studies. There are a number of excellent research teams, research institutions, national libraries, such as Academy of Social Sciences and the National Library localized in Beijing in addition to famous Universities such as Peking University, Renmin University of China, Tsinghua University. research project compared to the higher number of Beijing's other provinces, Consequently a relatively small proportion of project approval institutes are from Universities albeit the total number of the project approval is the highest in Beijing.

Concerning the project approval of library and information studies, Wuhan University ranked No. 1, where 46 projects were funded. Library as a major in Wuhan University has the right to grant doctoral degree (grade-1 discipline). Meanwhile the Information Resources Research Center of Wuhan University was approved by the Ministry of Education as humanities and social science research base. Therefore, this University is considered as a prestigious place in the library and information knowledge production. Moreover, Peking University, Renmin University of China, Chinese Academy of Sciences, China Science and Technology Institute, Chinese Academy of Social Sciences, and Shanghai Academy of Social Sciences are the main institutes responsive for library and information studies, with number of project approval for each of them reaching ca. 5-10. Universities and research institutes, as the main project approval units for National Social Science Foundation, are the main bases for library and information studies, where having good research conditions and excellent research talents.

\section{F. Excellent research teams}

The outstanding research teams and excellent research capabilities are the most important in library and information studies, which can be roughly judged according to the funding situation from National Social Science Foundation.

According to the survey, teams leading the research and development of library and information sciences are mainly three types: First, well-known scholars including Yuying Jiao, Bingsi Fan, Hanqing Hou, Jinfeng Yu, etc; Second, young researchers, including Ruhua Huang, Chen ZhuanFu Chen, Qinghua Zhu, etc; Third, young doctors, including Dan $\mathrm{Wu}$, Congjing Ran, Xiaoping Sheng,etc. Most of the researchers are real experts and scholars with a wealth of expertise, a sense of innovation in research and intellectual curiosity, who constitute the central force and lead the advancement and development of library and information studies. In recent years, many young people have joined the library and information studies. They are the new blood for our library and information research. Nevertheless, in the field of library and information studies in our country, highly talented people are still relatively rare, so research teams have to work hard continually for contributing the development of national information and knowledge production.

\section{CONCLUSIONS}

National library and information study is deemed important component of social science research, which promotes the theoretical innovation. National Social Science Foundation in library and information studies are mainly associated with major theoretical and practical issues in reform, opening-up and socialist modernization, which generally reflects in hot, focus and difficult problems/issues. Research papers, monographs, translations, and research reports are the major forms for the research outputs. Large number of the funded project is mainly concentrated in the economically developed and universities gathered areas. Beijing, Shanghai and several other regions have relatively high number of projects due to economic development and the University gathering effect. Colleges and universities containing excellent scientific research personnel and excellent scientific research strength, are the main units receiving project funding. Experts, scholars and doctoral researchers contribute greatly toward library and information studies. In recent years, a lot of young scholars joined the library and information research. 
Since National Social Science Foundation includes library and information sciences and literature studies as funding research projects in 1994 , the number of library and information studies projects has been growing constantly, suggesting of grants from the National Social Science Foundation promote the library and information studies. In recent years, due to the strong support of the CPC Central Committee and related authorities, the number of funds from National Social Science Foundation continues to grow. Meanwhile, the number of applications concerning the annual projects and experts for subject group evaluation and peer review evaluation are in constant growth; the project system is also improving. National policy plays an important role in both policy and financial support for the development of library and information studies. Nevertheless, there is a big problem associated with the knowledge production of library and information. Namely, library and information knowledge production is somehow limited by the planned intelligence production system. Therefore, we need to give attention to the innovation and future development of library and information and related projects.

\section{REFERENCES}

[1] National Planning Office of Philosophy and Social Science. Improve planning and management level, thrive philosophy and social sciences. Guangming Daily, 2010-10-27 (11)

[2] Xinjun Xu. Statistical analysis for the national social science funded projects over the past decade. Library \& Information, 2007 (4) : 103-106.

[3] Zhenhua Chen.New viewpoint concerning educationa and knowledge production. Journal of East China Normal University (Educational Sciences)， 2001（3） : 88-96.

[4] Dongsheng Zhai, Mingleji Wang, Yang Yu. Design of patent analysis system based on patent map and multi-agent. Journal of the China Society for Scientific and Technical Information, 2006,25（3）: 316-321

[5] Guohua Xiao, Shuming Xiong, Xian Zhang. Patent Map design and influencing factors. Information Studies: Theory \& Application, 2007 (3) : 372-377

[6] Xiaopei Ge. Patent map and its application in the biomedical field. Suzhou : Suzhou University, 2010

[7] Yan Chen, Yingyan Huang, Jiangguo Fang. information collection and analysis. Beijing: Tsinghua University Press, 2006. 